\title{
Correlation of systolic blood pressure with age and body mass index in native Papuan populations
}

\author{
Hypertension Research (2012) 35, 959-960; doi:10.1038/hr.2012.106; published online 12 July 2012
}

We read with great interest the recent article by Quan HL et al., ${ }^{1}$ which reported that very little is known about the epidemiology of the correlation between blood pressure (BP) and its predictors in developing countries. We have carried out field surveys on the indigenous people living in two regions of the world's least developed island, New Guinea, in Indonesia. We found that social globalization exerts an influence on the correlation between systolic BP (SBP) and age, and SBP and body mass index (BMI).

The Soroba village in the central highland (1600 m above sea level) in Papua, Indonesia, was one of the study sites. In this region, the indigenous people maintain a traditional way of life; men wear only penis sacks and women wear straw waistcoats. Taro and sweet potatoes are the chief foods of this indigenous population; salt and sugar are consumed in small amounts even today.

Bade, in the southern coastal lowland of Papua, was the other study site. Bade is located on the banks of a big river and has hence flourished as a transportation hub. In the 1970s, several non-Papuan Indonesian people moved to this region from other islands of Indonesia in search of a new niche. Indigenous Papuans in Bade are attired in shirts and trousers; rice is replacing the more traditional sago as the chief food. Salt and sugar intake have been increasing among the native Papuans living in Bade.

The study population consisted of 100 native Papuans aged 30 years or more $(\mathrm{M}: \mathrm{F}=46: 54$; mean age, 45.4 years) in the Soroba study group and $88(\mathrm{M}: \mathrm{F}=38: 50$; mean age, 54.0 years) in the Bade study group. We obtained the informed consent from all the participants. Sitting BP was measured twice after a 5-min rest by using an auto-sphygmomanometer (Omron, Kyoto, Japan, Hem7200); weight and height were also recorded. The mean of the two BP measurements were used for analysis. Hypertension (HT) was defined as either SBP $\geqslant 140 \mathrm{~mm} \mathrm{Hg}$ or diastolic BP (DBP) $\geqslant 90 \mathrm{~mm} \mathrm{Hg}$ or when the subject was already on anti-hypertensive medication.

Figure 1 shows the comparison of the correlation of SBP and age in the populations in Soroba and Bade. The SBP of native Papuans in Soroba did not show an increase with age, whereas that of the subjects in Bade increased significantly with age. The mean SBP and DBP were 118 and $73 \mathrm{~mm} \mathrm{Hg}$ in the Soroba group and 144 and $80 \mathrm{~mm} \mathrm{Hg}$ in the Bade study group, respectively, although it should be noted that the mean age of the subjects in Soroba was lower than that in Bade. Figure 2 shows the comparison of the correlation of SBP and DBP with BMI. SBP and DBP did not show any correlation with BMI in the Soroba population; in contrast, SBP and DBP showed significant correlation with BMI in the Bade population. The prevalence of HT was $8 \%$ in Soroba and $56 \%$ in Bade.

SBP is significantly correlated with age in most developed countries; very few

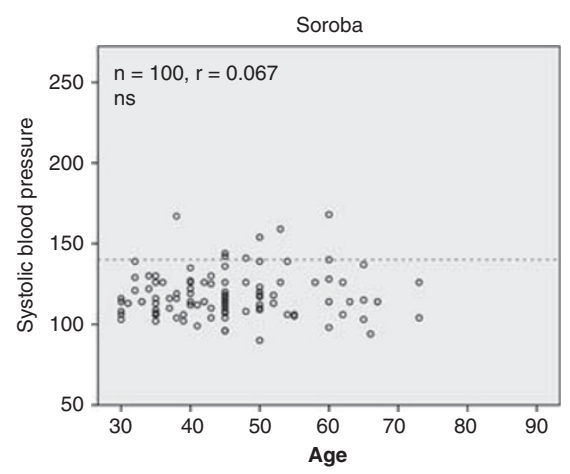

populations lacking the correlation between SBP and age have been reported. These include the Yanomamo and Xingu Indians in Brazil, ${ }^{2,3}$ the highlanders in Papua New Guinea, ${ }^{3}$ and the inhabitants of the Kotyang village in the Himalayas in Nepal. ${ }^{4}$ According to the INTERSALT study, incidence of high BP and its increase with age is associated with high sodium intake, low potassium intake, lack of exercise, obesity and high alcohol consumption. ${ }^{5}$ Specifically, sodium intake was found to be the strongest factor linking SBP with age. ${ }^{2}$ As these factors are associated with a modern lifestyle, it can be said that an increase in BP with age is an effect of the impact of social globalization on human physiology. In particular, it should be noted that a population such as the native Papuans living in Soroba still exists to this day, in which a significant correlation between SBP and age is yet to be found.

Our findings suggest that an increase of SBP with age is influenced by social globalization inter-mingled with changes in the lifestyle within the non-Caucasian, indigenous Papuan population.

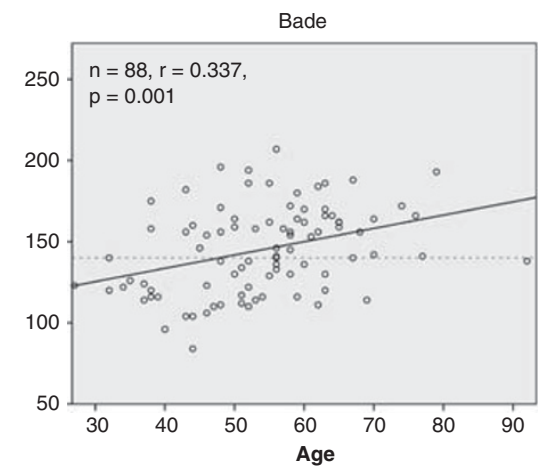

Figure 1 Correlation between systolic blood pressure and age in the populations of area of two regions in Papua: Soroba and Bade. A full color version of this figure is available at the Hypertension Research journal online. 

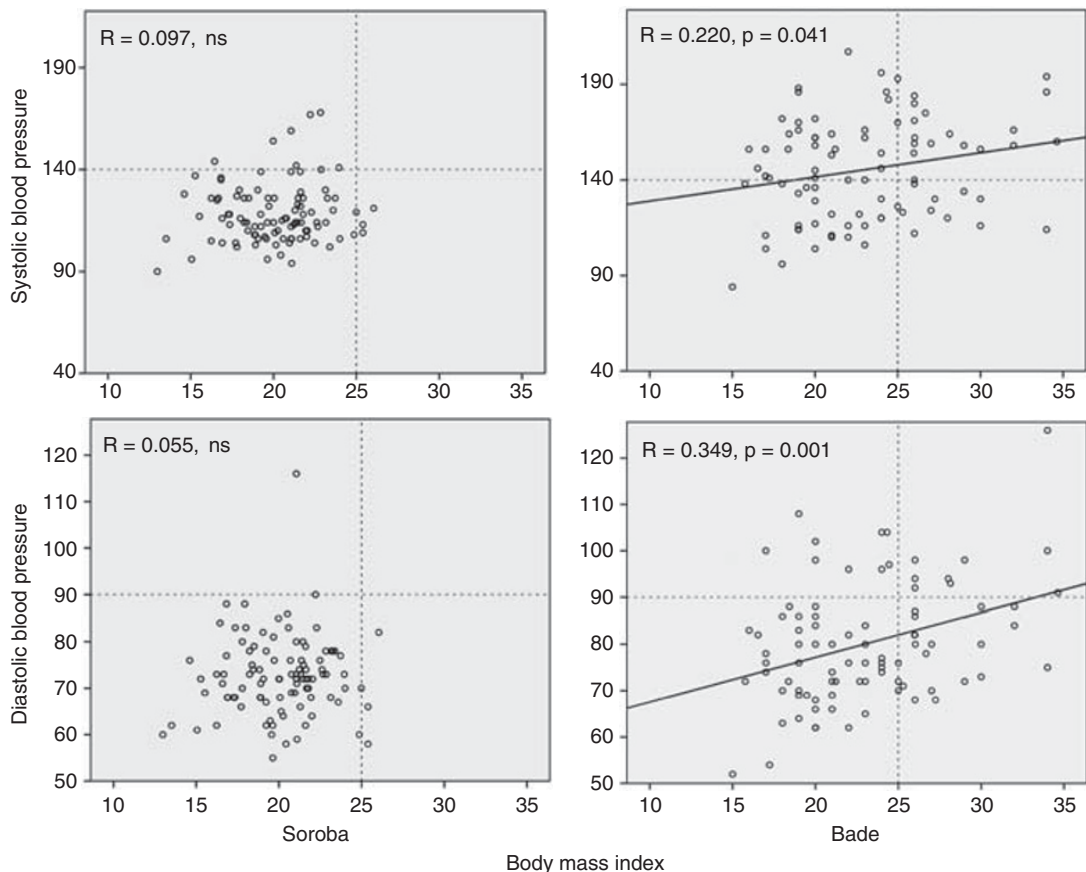

Figure 2 Correlation between blood pressure and body mass index in the populations of Soroba and Bade. A full color version of this figure is available at the Hypertension Research journal online.

\section{CONFLICT OF INTEREST}

The authors declare no conflict of interest.

\section{ACKNOWLEDGEMENTS}

The authors appreciate the help of all the study participants, village leaders and the staff of the health station in Soroba: Christha Z Tamburian MD from Puskesmas Bade, Pauline Watofa MD, ZA Wasaraka, Lazarus Revasy MA from the University of Cenderawasih and Andre Liem from PATGOM. Mr Amos SE was the translator.
The study was supported by grants from the Japanese Ministry of Education, Science and Culture (No. 21256005 and No. 22659141).

Michiko Fujisawa ${ }^{1}$, Yasuko Ishimoto ${ }^{2}$, Wenlin $\mathrm{Chen}^{3}$, Indrajaya Ida Bagus Manuaba ${ }^{4}$, Eva Garcia del Saz ${ }^{5}$, Kiyohito Okumiya ${ }^{6}$, Taizo Wada $^{2}$, Yumi Kimura ${ }^{2}$, Hissei Imai ${ }^{3}$ and Kozo Matsubayashi ${ }^{2,3}$

${ }^{1}$ Wildlife Research Center, Kyoto University, Kyoto, Japan; ${ }^{2}$ Center for Southeast
Asian Studies, Kyoto University, Kyoto, Japan; ${ }^{3}$ Department of Field Medicine, Kyoto University, Kyoto, Japan; ${ }^{4}$ Department of Neurology, Wamena General Hospital, Papua, Indonesia; ${ }^{5}$ Center for Regional and International Collaboration, Kochi University, Kochi, Japan and ${ }^{6}$ Research Institute for Humanity and Nature, Kyoto, Japan

E-mail: fujisawa.michiko.2u@kyoto-u.ac.jp

1 Quan HL, Blizzard CL, Venn AJ, Thy AB, Luc PH, Sharman JE. Blood pressure and body mass index: comparison of the associations in the Caucasian and Asian populations. Hypertens Res 2012; 35 523-530.

2 Oliver WJ, Cohen EL, Neel JV. Blood pressure, sodium intake, and sodium related hormones in the Yanomamo Indians, a 'No-salt' culture. Circulation 1975; 52 146-151.

3 Carvalho JJ, Baruzzi RG, Howard PF, Poulter N, Alpers MP, Franco LJ, Marcopito LF, Spooner VJ, Dyer AR, Elliott P. Blood pressure in four remote populations in the INTERSALT study. Hypertension 1989; 14: 238-246.

4 Kawasaki T, Itoh K, Uezono K, Ogaki T, Yoshimizu Y, Kobayashi S, Osaka T, Ogata M, Dhungel S, Sharma S, Acharya GP. Investigation of high salt intake in a Nepalese population with low blood pressure. J Hum Hypertens 1993; 7: 131-140.

5 Rodriguez BL, Labarthe DR, Huang B, Lopez-Gomez J. Rise of blood pressure with age. New evidence of population differences. Hypertension 1994; 24 : 779-785.

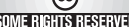

This work is licensed under the Creative Commons AttributionNonCommercial-No Derivative Works 3.0 Unported License. To view a copy of this license, visit http://creativecommons.org/ licenses/by-nc-nd/3.0/ 